J. Clin. Chem. Clin. Biochem.

Vol. 28, 1990, pp. 95-105

(C) 1990 Walter de Gruyter \& Co. Berlin - New York

\title{
Effect of Glucose upon Alkaline Picrate: A Jaffé Interference
}

\author{
By S. Viraraghavan and $K$. G. Blass \\ Department of Chemistry, University of Regina, Regina, Saskatchewan, Canada
}

(Received January 17/September 1, 1989)

Summary: The reactivity of glucose in aqueous alkaline picrate was investigated by spectrophotometry and polarography at $25^{\circ} \mathrm{C}$ in $0.51 \mathrm{~mol} / 1$ sodium hydroxide. Thin-layer chromatography and infrared spectroscopy studies have conclusively identified the presence of picramic acid in 5:1 and 10:1 glucose picrate test solutions incubated at $25^{\circ} \mathrm{C}$.

The polarographic data of an alkaline picrate blank with a concentration of $0.284 \mathrm{mmol} / 1$, show three welldefined nitro group reduction waves with approximate half-wave potentials of $-0.62 \mathrm{~V},-0.78 \mathrm{~V}$, and $-0.93 \mathrm{~V}$ and a fourth broad wave appearing near $-1.31 \mathrm{~V}$ versus a saturated calomel electrode. The addition of glucose to alkaline picrate resulted in a decreased diffusion current for reduction waves $1-3$, with little change in reduction wave 4 . The reactivity of test solutions containing glucose: picrate in $1: 1,2: 1,5: 1$ and 10:1 molar ratios was investigated at varied time intervals between 10 and 180 minutes.

The absorption spectra of a 10:1 glucose:picrate solution shifted from $356 \mathrm{~nm}$ to $375 \mathrm{~nm}$ and a broad tailing shoulder absorbance formed in the $450-600 \mathrm{~nm}$ region. An orange coloured minor product, separated by thin-layer chromatography, was observed to fluoresce. The maximum excitation and emission wavelengths were $318 \mathrm{~nm}$ and $545 \mathrm{~nm}$, respectively. A major, red-coloured product was isolated and identified as picramic acid by infrared spectroscopy. For 10:1 glucose:picrate test solutions incubated at $25^{\circ} \mathrm{C}$, picramic acid formed within 10 minutes. Within the first minute, the colour was observed to change from yellow to orange and then to red.

\section{Introduction}

Jaffé reported in 1886 that a red colour formed at room temperature when creatinine was reacted with picric acid at an alkaline $\mathrm{pH}$ (1). Modified Jaffé methods are currently still the most widely employed procedure for the measurement of creatinine in biological samples. However, dependent upon the reaction conditions employed and the mode of measurement, numerous substances have been reported to interfere in the Jaffé reaction e.g. pyruvate $(2,3)$, acetone $(4,5)$, acetoacetate $(3,6,7), \mathrm{NaOH}(8)$, bilirubin $(9)$, protein $(10,11)$, glucose $(5,12-14)$, etc.

Jaffé showed that glucose did not react with alkaline picrate at ambient temperature, except after an extended period of time (1). He reported that upon warming, an immediate blood red-coloured reduction product of picric acid formed. Other investigators had also reported that a red colour formed upon the application of heat $(2,4,12,15-19)$. Weise \& Tropp (4) mentioned that after a long incubation period in the cold, glucose gave a positive reaction with alkaline picrate. At room temperature, in the presence of a glucose concentration ten times higher than that in the normal serum, a colour was produced after 30 minutes (2). Lauson (20) noticed a suppression of colour and reported that the sum of the chromogen values of a solution of pure glucose and of pure creatinine, separately determined, was greater than the total chromogen concentration of the same quantities of the two in combination. Furthermore, the decrease in colour became more apparent with time 
after the addition of alkaline picrate. Kostir \& Rabek classified glucose under Jaffé positive behaviour after heat treatment or upon extended incubation in the cold. Husdan \& Rapoport (14) observed that the presence of glucose- $(700 \mathrm{mg} / \mathrm{dl} ; 38.9 \mathrm{mmol} / \mathrm{l})$ led to high results for serum total creatinine with an error of 15 to $20 \%$. More recently, Cook (21) carried out the Jaffé reaction in the presence of glucose at $21^{\circ} \mathrm{C}$ and $33^{\circ} \mathrm{C}$, respectively, and concluded that the rate of colour development depended upon the glucose concentration and temperature. A high concentration of glucose $(55 \mathrm{mmol} / \mathrm{l})$ caused a decrease in the rate of creatinine picrate formation, probably attributable to the competition for picrate (22). Cook classified glucose as an interfering substance which, at room temperature, slowly reduced alkaline picrate to red picramate, probably through a colourless transition complex. He reported an absorbance maximum of 482 $\mathrm{nm}$ for glucose picrate solution after boiling when measured against an alkaline picrate blank (21).

Extensive polarography, spectrophotometry and chromatography studies have been undertaken to investigate the reactivity of glucose with alkaline picrate at $25^{\circ} \mathrm{C}$ and to relate the results to the Jaffé reaction.

\section{Materials and Methods}

Picric acid (2,4,6-trinitrophenol) was „Analar“ grade (crystals in water weight fraction 0.5) from BDH chemicals, Toronto, Ontario, Canada M8Z 1K5. Anhydrous $D(+)$ glucose, ethyl acetate, isopropanol and sodium hydroxide were certified A. C. S. grade from Fisher Scientific Co., Fairlawn, New Jersey, USA, 07410. A. C. S. grade mercury was from Johnson Matthey Limited, Toronto, Ontario, Canada, M6M 4M1. Nitrogen gas, 99.99\% purity, was from Canadian Liquid Air Ltd., Regina, Saskatchewan, Canada, S4P 3A2. Picramic acid and infrared spectroscopy grade potassium bromide was purchased from Sigma Chemical Company, St. Louis, Missouri, USA, 63178. Ammonium hydroxide $\left(28-30 \% \mathrm{NH}_{3}\right)$ and hydrochloric acid were from Canadian Industries Ltd., Winnipeg, Manitoba, Canada, R2G 2X2.

Model 4001 Pulse/DC Sargent-Welch Polarograph ${ }^{\mathrm{TM}}$ was from Sargent-Welch Scientific Co., Skokie, Illinois, USA, 60077. A Haake W13 water bath and a Hake D-8 circulator pump were from Fisher Scientific Ltd., Winnipeg, Manitoba, Canada, R2X $2 \mathrm{~V} 7$.

Metrohm AG9100 Herisau reference electrode was from Brinkmann Instruments Canada Limited, Rexdale, Ontario, Canada, M9W 4Y5. A Model 8450A UV/VIS spectrophotometer and a Model 7245A-plotter printer were from Hewlett-Packard, San Diego, California, USA, 92127. Type N-1 spectrophotometric cells (cuvettes) with a light path of $2 \mathrm{~mm}$ were from Norell Inc., Landisville, New Jersey, USA, 08326 . Whatman $20 \times 20 \mathrm{~cm}$ K5 silica gel TLC plates $(250 \mu \mathrm{m}$ thickness) were purchased from Canlab, Winnipeg, Manitoba, Canada, R3J 3V9. Samples were applied to the TLC plates with $10 \mu \mathrm{l}$ Hamilton syringes from Hamilton Company, Reno, Nevada, USA, 89510. The chromatography plates were heat-activated in a Blue $M$ oven from Blue M Electric, Blue Island, Illinois, USA, 60406. Chromatography plates were developed in an Eastman Chromatogram Chamber plate set from Eastman-Kodak, Rochester, New York, USA, 14650. Chromatograms were examined under long wave $(375 \mathrm{~nm})$ and short wave $(253.7 \mathrm{~nm})$ ultraviolet light with a universal U.V. unit from Gelman, Ann Arbor, Michigan, USA, 48106. Photography was by the Audio-Visual Service, University of Regina, Saskatchewan, Canada, S4S 0A2.

All pH measurements were performed with a Fisher Accumet pH meter, Model 825 MP from Fisher Scientific Co., Fairlawn, New Jersey, USA, 07140. A Mark I Spectrofluorometer with a TLC scanner attachment was from Farrand Optical Co., Inc. Valhalla, New York, USA, 10595. Infrared spectra were recorded with a Perkin-Elmer Model 267 infrared grating spectrophotometer from Perkin-Elmer Canada, Ltd., Montreal, Quebec, Canada, H4P 2B7.

Saturated picric acid solution at $25^{\circ} \mathrm{C}$ was prepared by adding excess picric acid to a $500 \mathrm{ml}$ volumetric flask. Picric acid solubility is $13 \mathrm{~g} / 1$ at $25^{\circ} \mathrm{C}(23)$. The solution, in a dark brown glass bottle, was maintained at $25^{\circ} \mathrm{C}$ in a constant temperature water bath. Clear saturated picric acid solution was used for the study. A stock $2.04 \mathrm{~mol} / \mathrm{l} \mathrm{NaOH}$ solution was prepared by dissolving $160 \mathrm{~g}$ of $\mathrm{NaOH}$ in a 21 volumetric flask which contained approximately 11 of distilled water. The solution was brought to room temperature prior to adjusting the volume with distilled water. Working solutions of $1.02 \mathrm{~mol} / 1$ and 0.51 $\mathrm{mol} / \mathrm{l}$ were prepared by dilution with distilled water.

\section{Polarography stability studies}

The reference, auxiliary (counter), and working electrodes were a saturated calomel electrode, a wire platinum electrode, and a dropping mercury electrode, respectively. The characteristics of the dropping mercury electrode were $\mathrm{m}=17.68 \mathrm{mg} \mathrm{s}^{-1}$; $\mathrm{t}=6.9 \mathrm{~s}$; and a capillary constant of $\mathrm{m}^{2 / 3} \mathrm{t}^{1 / 6}=9.38 \mathrm{mg}^{2 / 3}$ $\mathrm{s}^{-1 / 2}$.

The height of the mercury column was $70.5 \mathrm{~cm}$. Direct current polarography was performed within a potential range of -0.4 to -1.80 volts versus saturated calomel electrode, with a scanning time of 7 minutes. A mercury drop rate of 0.5 seconds/ drop was maintained throughout the study.

For the polarography stability study, a dilute alkaline picrate blank solution was prepared. A $0.5 \mathrm{ml}$ volume of saturated picric acid was pipetted into approximately $40 \mathrm{ml}$ of distilled water in a $100 \mathrm{ml}$ volumetric flask immersed in a $25^{\circ} \mathrm{C}$ water bath. A $50 \mathrm{ml}$ volume of $1.02 \mathrm{~mol} / 1 \mathrm{NaOH}$ was added. The flask was made up to volume with distilled water. A $50 \mathrm{ml}$ aliquot of the blank solution was transferred to a $25^{\circ} \mathrm{C}$ waterjacketed electrolysis vessel. The solution was purged with nitrogen gas and polarographic analysis was started at exactly 30 minutes of incubation time. Polarographic analyses were also performed at 1,2, and 3 hours. The solution was purged with nitrogen gas after each analysis.

Polarography stability studies of aqueous glucose : alkaline picrate test solutions were performed. To a freshly prepared 50 $\mathrm{ml}$ aliquot of alkaline picrate blank solution, exactly $0.0026 \mathrm{~g}$ of glucose was added and the timing was started. This produced a test solution containing glucose and picrate in approximately 1:1 molar ratio. Nitrogen gas was purged for the entire reaction time. Polarographic analyses were performed at 30 minute intervals for a 3 hour duration as described above. Polarographic analysis of a $5: 1$ glucose:picrate test solution was similarly performed.

\section{Polarography studies}

All subsequent studies were performed in saturated picric acid diluted with an equal volume of sodium hydroxide. A $5 \mathrm{ml}$ volume of saturated picric acid was pipetted into a brown bottle immersed in a $25^{\circ} \mathrm{C}$ water bath. A $5 \mathrm{ml}$ volume of $1.02 \mathrm{~mol} / \mathrm{l}$ $\mathrm{NaOH}$ was added and the resulting alkaline picrate blank solution was mixed and purged with nitrogen gas for $10 \mathrm{~min}$ utes. A $0.1 \mathrm{ml}$ aliquot and a $0.5 \mathrm{ml}$ aliquot of the blank solution 
were immediately withdrawn and diluted for blank spectrophotometric and polarographic analyses, respectively. Subsequently, aliquots of the blank solution were taken at 1,2 , and 3 hours of incubation time and similarly diluted and subjected to polarographic and spectrophotometric analyses.

A $0.5 \mathrm{ml}$ volume of alkaline picrate blank solution was added to a $50 \mathrm{ml}$ volumetric flask containing nitrogen-purged 0.51 $\mathrm{mol} / 1 \mathrm{NaOH}$. The blank solution was adjusted to volume with the sodium hydroxide solution and transferred to a $25^{\circ} \mathrm{C}$ waterjacketed electrolysis vessel. The first aliquot of the blank solution served as a 0 time reference point for comparison purposes. Polarographic analysis of the 0 time blank was performed as described above. Similarly $0.5 \mathrm{ml}$ aliquots of the blank solution were withdrawn and diluted after 1,2 and 3 hours of reaction time. Polarographic analyses were similarly performed.

All glucose alkaline picrate test solutions consisting of $5 \mathrm{ml}$ of saturated picric acid, $5 \mathrm{ml}$ of $1.02 \mathrm{~mol} / 1 \mathrm{NaOH}$ and glucose were incubated at $25^{\circ} \mathrm{C}$. A $0.0511 \mathrm{~g}$ weight of $D(+)$-glucose was added to a freshly prepared, nitrogen-purged, alkaline picrate blank solution. The test solution was immediately mixed and the timing was started. This produced a test solution containing a glucose : picrate in a molar ratio of $1: 1$. Polarographic analyses were performed at $0,1,2$ and 3 hours of reaction time.

Test solutions containing glucose:picrate in molar ratios of $2: 1,5: 1$ and $10: 1$ were prepared. Polarographic analyses were similarly performed for test aliquots at $0,1,2$ and 3 hours of reaction time. The above procedure was similarly reproduced in triplicate.

A 10:1 glucose : picrate test solution was prepared as previously described. Polarographic analyses were performed as described above with measurements being taken at 10 minute intervals for a 2 hour duration. The entire procedure was reproduced in triplicate.

Polarography of commercial picramic acid in $0.51 \mathrm{~mol} / 1 \mathrm{NaOH}$ was similarly performed in triplicate as described for the alkaline picrate blank analyses. A 10:1 glucose: picramic acid in $0.51 \mathrm{~mol} / \mathrm{l} \mathrm{NaOH}$ was similarly prepared, and polarographic analyses were performed with measurements being taken at $1 / 2$ hour intervals for a 2 hour duration.

\section{Acid/alkali nitro group regeneration studies}

A $5 \mathrm{ml}$ volume of saturated picric acid was mixed with $5 \mathrm{ml}$ of $1.02 \mathrm{~mol} / 1 \mathrm{NaOH}$ and purged with nitrogen gas. A $0.5 \mathrm{ml}$ volume of the blank solution was diluted to $50 \mathrm{ml}$ with 0.51 $\mathrm{mol} / 1 \mathrm{NaOH}$ which was already degassed. Polarograms were recorded at 0,1 , and 2 hours of incubation time. At the end of 2 hours, the blank solution was acidified to a $\mathrm{pH}$ of 1.4 with $12 \mathrm{ml}$ of $3 \mathrm{~mol} / \mathrm{l} \mathrm{HCl}$. The blank was returned to an alkaline $\mathrm{pH}$ of 12.8 by the addition of $3 \mathrm{ml}$ of $4 \mathrm{~mol} / \mathrm{l} \mathrm{NaOH}$ and a polarogram was recorded. Polarographic analyses were performed for diluted aliquots of $1: 1$ glucose: picrate test solutions at 0 and 5 hours of reaction time. Acid/alkali treatment of the 5 hour test solution was performed as described above. Polarographic analyses were similarly performed for $2: 1$ and $5: 1$ glucose:picrate test solution at 0 and 2 hours of reaction time. Acid/alkali treatment and polarographic analyses of 2 hour test solutions were similarly performed. Polarographic analyses were performed for $10: 1$ glucose : picrate test solution at 0 and $11 / 2$ hours of reaction time. Acid/alkali treatment and polarographic analysis of the $11 / 2$ hour test solution were performed as described above.

\section{Spectrophotometry studies}

A $0.1 \mathrm{ml}$ volume of a blank solution was withdrawn and added to a $10 \mathrm{ml}$ volumetric flask containing $0.51 \mathrm{~mol} / 1 \mathrm{NaOH}$. This produced a $10 \mathrm{ml}$ volume of diluted blank solution which was used for UV/VIS spectrophotometric analysis. A cuvette with a $0.2 \mathrm{~mm}$ light path was employed. Spectrophotometric analysis of the diluted 0 hour aliquot was performed at $25^{\circ} \mathrm{C}$ between $200 \mathrm{~nm}$ and $650 \mathrm{~nm}$ against a distilled water blank. A $0.1 \mathrm{ml}$ aliquot of the blank solution was similarly withdrawn and diluted after 1,2, and 3 hours of reaction time. Spectrophotometric analyses were performed as described above. Solutions containing glucose:picrate in molar ratios of $1: 1,2: 1,5: 1$ and 10:1 were similarly performed in duplicate.

A 10:1 glucose:picrate test solution was prepared as previously described. Spectrophotometric analyses were performed as described above with measurements being taken at 10 minute intervals for a 2 hour duration. The entire procedure was reproduced in triplicate.

\section{Thin-layer chromatography studies}

Thin-layer chromatography (TLC) was performed on $20 \times 20$ $\mathrm{cm}$, Whatman $\mathrm{K} 5$, silica gel plates. Activated plates were preheated in a $110^{\circ} \mathrm{C}$ oven for 30 minutes, and stored above silica gel in a desiccator at room temperature prior to use. A test solution containing a 1:1 molar ratio of glucose : picrate was prepared as previously described. At 0 time a $10 \mu \mathrm{l}$ aliquot of test solution was withdrawn and spotted onto a heat-activated TLC plate, at a distance of $2 \mathrm{~cm}$ from the left edge and $2 \mathrm{~cm}$ from the bottom. Test aliquots withdrawn at 1/2,1,11/2, 2 and 3 hours of incubation time were similarly applied at $2 \mathrm{~cm}$ intervals. Test solutions containing glucose:picrate in molar ratios of $2: 1,5: 1$ and $10: 1$ were similarly prepared and tested as described above. A reference material consisting of aqueous saturated picramic acid was similarly applied to the chromatography plate. Chromatography solvent system I consisted of ethyl acetate : isopropanol : ammonium hydroxide: water $(60+$ $28+8+4$, by vol.) (24). Freshly prepared solvent system I was mixed and allowed to stand at room temperature for 15 minutes prior to use. A $150 \mathrm{ml}$ volume of the solvent mixture was transferred to the chromatography trough. The chromatography chamber was assembled and solvent system I was allowed to migrate a distance of $13 \mathrm{~cm}$ above the origin. The solvent migration time was approximately 80 minutes. The plate was air-dried and visually examined. The chromatogram was also examined under UV light. The procedure presented above was reproduced in triplicate.

The aliquots containing glucose : picrate in a 10:1 molar ratio were spotted on a separate TLC plate at 10 minute sampling intervals up to 90 minutes.

\section{Spectrofluorometry studies}

UV examination of the TLC separation of products of $1: 1$, $2: 1,5: 1$ and $10: 1$ glucose: picrate test solutions showed a fluorescent product spot under alkaline reaction conditions. A Farrand Mark I spectrofluorometer equipped with a xenon arc light source and a TLC scanner attachment was employed to measure the maximum excitation and emission spectra of the fluorophore. The xenon arc light source was aligned employing a quartz standard. TLC pickup slit dimensions were $1 \times 14$ $\mathrm{mm}$. Excitation and emission slits were 10,10, and 10,1 nm respectively. The excitation and emission filters were 7-54 and 3-72, respectively. Emission spectra were taken between $400 \mathrm{~nm}$ and $700 \mathrm{~nm}$ with the excitation wavelength set at $375 \mathrm{~nm}$. Excitation spectra were recorded between $500 \mathrm{~nm}$ and $250 \mathrm{~nm}$ with the emission wavelength set at $545 \mathrm{~nm}$.

\section{Preparation of glucose : picrate reaction products}

Reports are available for the preparation of reduction products of picric acid using various reducing agents $(25-27)$. But no literature is available for the preparation of glucose:picrate reduction products. Based on the references cited and with slight modification of the procedure of Egerer (25), picramic acid isolation was attempted. 
A $1.3 \mathrm{~g}$ quantity of dry picric acid was dissolved in $75 \mathrm{ml}$ of boiling hot distilled water in a $250 \mathrm{ml}$ brown glass bottle. The solution was cooled to $25^{\circ} \mathrm{C}$ in a water bath and purged with nitrogen gas. A $25 \mathrm{ml}$ volume of $2.04 \mathrm{~mol} / \mathrm{l} \mathrm{NaOH}$ was added slowly to minimize temperature rise. A 10.22 g quantity of solid $D(+)$-glucose was quickly added and the reaction mixture was stirred well. The resulting solution, a 10:1 glucose:picrate molar ratio in $0.51 \mathrm{~mol} / 1 \mathrm{NaOH}$, was incubated for 90 minutes at $25^{\circ} \mathrm{C}$. Product isolation was performed by a modified procedure of Anslow \& King (28). The bottle containing the reaction mixture was placed in an ice bath and cooled below $10^{\circ} \mathrm{C}$. A $40 \mathrm{ml}$ volume of ice-cold $3 \mathrm{~mol} / 1 \mathrm{HCl}$ was added quickly. The ice-cold acidic mixture of $\mathrm{pH} 2$ was stirred for half an hour to facilitate product precipitation. According to Anslow \& King most of the unreacted picric acid remained in solution. Precipitate I was isolated by filtration, washed with a small amount of cold dilute $\mathrm{HCl}$, and stored in a refrigerator. Traces of product were recovered from filtrate I by the procedure of Hodgson \& Ward (27). Filtrate I was extracted twice with $25 \mathrm{ml}$ of benzene, forming benzene extract I. Extract I was evaporated to dryness in a Büchi rotary evaporator and added to precipitate I.

Precipitate I was purified according to the procedure of Egerer (25). Precipitate I was added to a $400 \mathrm{ml}$ volume of boiling distilled water with constant stirring. The undissolved residue, consisting mainly of diamino product (25), was removed by filtration and discarded. This produced filtrate II which was allowed to cool to room temperature. Filtrate II was evaporated on a rotary evaporator. The residue was dissolved in ethanol, filtered and evaporated to dryness. This produced residue II.
Commercially available picramic acid from Sigma Chemical Co. was employed as reference material. The reference picramic acid was applied as a streak to a TLC plate. Colour and $R_{f}$ values were used to identify the product (24). After chromatographic separation, employing solvent system I, a reddishbrown coloured band of $R_{r}$ near 0.48 was scraped off the chromatogram. A $10 \mathrm{ml}$ volume of ethanol was used to elute the reddish-brown coloured picramic acid from the silica gel. The solvent was evaporated and the melting point of the picramic acid was established. Similarly, residue II was dissolved in few drops of $0.51 \mathrm{~mol} / 1 \mathrm{NaOH}$ and spotted on a separate TLC plate. Chromatographic separation was achieved using the above solvent system I. A reddish-brown coloured product whose band was similar to the picramic acid, was scraped off the chromatogram, and the product was eluted from silica gel with $10 \mathrm{ml}$ of ethanol. The melting point of the dry product was determined.

Infrared spectroscopy of glucose : picrate reaction product

A potassium bromide $(\mathrm{KBr})$ blank disk of $1.5 \mathrm{~mm}$ diameter was formed under vacuum. The infrared spectrum of the blank was recorded on a Perkin-Elmer Model 267 infrared grating spectrometer. A $\mathrm{KBr}$ disk containing micro amounts of the isolated product was similarly prepared and its IR spectrum was recorded. Another $\mathrm{KBr}$ disk containing the reference picramic acid material was similarly prepared and an IR spectrum was recorded. IR spectra of the product and the reference material were compared.

Tab. 1. Stability studies of diluted alkaline picrate and glucose : diluted picrate ${ }^{1}$ in $1: 1$ and $5: 1$ molar ratio test solutions incubated at $25^{\circ} \mathrm{C}$

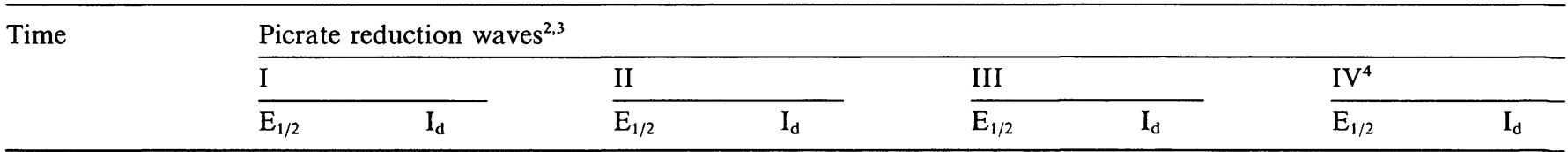

\section{$0: 1$ Alkaline picrate blank}

\begin{tabular}{|c|c|c|c|c|c|c|c|c|}
\hline $1 / 2 \mathrm{~h}$ & -0.62 & 1.18 & -0.78 & 0.93 & -0.93 & 1.20 & -1.33 & 1.40 \\
\hline $1 \mathrm{~h}$ & -0.62 & 1.15 & -0.78 & 0.93 & -0.93 & 1.20 & -1.33 & 1.42 \\
\hline $2 \mathrm{~h}$ & -0.62 & 1.15 & -0.78 & 0.93 & -0.93 & 1.20 & -1.33 & 1.42 \\
\hline $3 \mathrm{~h}$ & -0.62 & 1.15 & -0.78 & 0.93 & -0.93 & 1.20 & -1.33 & 1.42 \\
\hline
\end{tabular}

\section{1:1 Glucose : picrate diluted test}

$\begin{array}{llllllll}1 / 2 \mathrm{~h} & -0.62 & 1.20 & -0.78 & 0.95 & -0.93 & 1.12 & -1.32 \\ 1 \mathrm{~h} & -0.62 & 1.20 & -0.78 & 0.95 & -0.93 & 1.12 & -1.32 \\ 11 / 2 \mathrm{~h} & -0.62 & 1.20 & -0.78 & 0.95 & -0.93 & 1.12 & -1.32 \\ 2 \mathrm{~h} & -0.62 & 1.20 & -0.78 & 0.95 & -0.93 & 1.12 & -1.32 \\ 21 / 2 \mathrm{~h} & -0.62 & 1.20 & -0.78 & 0.95 & -0.93 & 1.12 & -1.45 \\ 3 \mathrm{~h} & -0.62 & 1.20 & -0.78 & 0.95 & -0.93 & 1.12 & -1.32\end{array}$

\section{5:1 Glucose : picrate diluted test}

\begin{tabular}{|c|c|c|c|c|c|c|c|c|}
\hline $1 / 2 \mathrm{~h}$ & -0.62 & 1.15 & -0.78 & 0.95 & -0.93 & 1.20 & -1.32 & 1.50 \\
\hline $1 \mathrm{~h}$ & -0.62 & 1.15 & -0.78 & 0.95 & -0.93 & 1.20 & -1.32 & 1.50 \\
\hline $11 / 2 \mathrm{~h}$ & -0.62 & 1.15 & -0.78 & 0.95 & -0.93 & 1.20 & -1.32 & 1.50 \\
\hline $2 \mathrm{~h}$ & -0.62 & 1.15 & -0.78 & 0.95 & -0.93 & 1.20 & -1.32 & 1.50 \\
\hline
\end{tabular}

\footnotetext{
${ }^{1}$ Saturated picric acid solution was diluted 200 times with $0.51 \mathrm{~mol} / 1 \mathrm{NaOH}$. Refer to text for complete details.

2 The half-wave potential $\left(\mathrm{E}_{1 / 2}\right)$ is expressed in volts versus a saturated calomel electrode.

3 The diffusion current $\left(I_{d}\right)$ is expressed in microamperes.

${ }^{4}$ Reduction wave IV was diffuse and not well defined. Approximate $E_{1 / 2}$ and $I_{d}$ measurements are presented.
} 


\section{Results}

Polarographic analysis of diluted alkaline picrate blank solutions in $0.51 \mathrm{~mol} / 1 \mathrm{NaOH}$ showed three well-defined reduction waves with average $\mathrm{E}_{1 / 2}$ values of $-0.62,-0.78$ and $-0.93 \mathrm{~V}$ and a broad fourth reduction wave of $-1.33 \mathrm{~V}$ versus a saturated calomel electrode.

For the stability study, the diffusion currents $\left(I_{d}\right)$ of $1: 1$ glucose: diluted picrate test solutions were calculated for 1,2 , and 3 hours. The $I_{d}$ 's of reduction wave 1 were compared with a corresponding alkaline picrate blank. A stability study was similarly performed for 5:1 glucose: diluted picrate test solutions (tab. 1). No significant change in $I_{d}$ was observed during 2 hours of testing.

For test solutions incubated in concentrated form, a general decrease in diffusion current for the first three waves was recorded with increasing glucose concentration and lengthened incubation time (see tab. 2). For test solutions containing glucose: picrate in $1: 1$ molar ratio, a very slight decrease in $I_{d}$ was noticeable after one hour of reaction time. Typical polarograms of $1: 1,2: 1,5: 1$ and $10: 1$ glucose: picrate test solutions incubated in concentrated form for one hour in $0.51 \mathrm{~mol} / 1 \mathrm{NaOH}$ are shown in figure 1 . The decrease in the diffusion current for the first three re-

Tab. 2. Polarographic results of the nitro group reduction waves of alkaline picrate blank and glucose : picrate $1: 1,2: 1$, and $5: 1$ molar ratio test solutions in $0.51 \mathrm{~mol} / \mathrm{l} \mathrm{NaOH}$.

Time

\section{Picrate reduction waves ${ }^{1,2}$}

\begin{tabular}{|c|c|c|c|c|c|c|}
\hline I & & II & & III & & $\mathrm{IV}^{3}$ \\
\hline$E_{1 / 2}$ & $I_{d}$ & $\overline{E_{1 / 2}}$ & $\mathrm{I}_{\mathrm{d}}$ & $\overline{E_{1 / 2}}$ & $I_{d}$ & $\overline{E_{1 / 2}}$ \\
\hline
\end{tabular}

0:1 Alkaline picrate blank

Blank
$1 \mathrm{~h}$
$2 \mathrm{~h}$
$3 \mathrm{~h}$

$\begin{array}{ll}-0.62 & 1.20 \\ -0.62 & 1.24 \\ -0.62 & 1.25 \\ -0.63 & 1.25\end{array}$

$\begin{array}{ll}-0.78 & 1.05 \\ -0.78 & 1.03 \\ -0.78 & 1.05 \\ -0.78 & 1.03\end{array}$

$\begin{array}{ll}-0.93 & 1.28 \\ -0.93 & 1.30 \\ -0.93 & 1.17 \\ -0.93 & 1.23\end{array}$

$\begin{array}{lr}-1.32 & 1.50 \\ -1.30 & 1.50 \\ -1.31 & 1.46 \\ -1.31 & -1.50\end{array}$

$1: 1$ Glucose: picrate test

\begin{tabular}{|c|c|c|c|c|c|c|c|c|}
\hline Blank $^{4}$ & -0.62 & 1.25 & -0.78 & 0.87 & -0.93 & 1.10 & -1.32 & 1.50 \\
\hline $\begin{array}{l}1 \mathrm{~h} \\
\% \text { decrease }\end{array}$ & -0.63 & $\begin{array}{l}1.20 \\
4.00 \%\end{array}$ & -0.79 & 0.87 & -0.93 & 1.10 & -1.31 & 1.50 \\
\hline $\begin{array}{l}2 \mathrm{~h} \\
\% \text { decrease }\end{array}$ & -0.62 & $\begin{array}{c}1.11 \\
11.6 \%\end{array}$ & -0.79 & $\begin{array}{l}0.79 \\
8.60 \%\end{array}$ & -0.93 & $\begin{array}{l}1.03 \\
6.36 \%\end{array}$ & -1.30 & 1.43 \\
\hline $\begin{array}{l}3 \mathrm{~h} \\
\% \text { decrease }\end{array}$ & -0.62 & $\begin{array}{c}1.00 \\
20.4 \%\end{array}$ & -0.78 & $\begin{array}{c}0.75 \\
13.2 \%\end{array}$ & -0.93 & $\begin{array}{c}0.98 \\
11.4 \%\end{array}$ & -1.30 & 1.46 \\
\hline \multicolumn{9}{|c|}{ 2:1 Glucose : picrate test } \\
\hline Blank $^{4}$ & -0.63 & 1.24 & -0.79 & 0.90 & -0.93 & 1.24 & -1.32 & 1.20 \\
\hline $\begin{array}{l}1 \mathrm{~h} \\
\% \text { decrease }\end{array}$ & -0.63 & $\begin{array}{c}1.00 \\
19.8 \%\end{array}$ & -0.79 & $\begin{array}{c}0.81 \\
10.3 \%\end{array}$ & -0.93 & $\begin{array}{c}1.09 \\
11.9 \%\end{array}$ & -1.31 & 1.29 \\
\hline $\begin{array}{l}2 \mathrm{~h} \\
\% \text { decrease }\end{array}$ & -0.62 & $\begin{array}{c}0.71 \\
42.3 \%\end{array}$ & -0.78 & $\begin{array}{c}0.64 \\
28.8 \%\end{array}$ & -0.93 & $\begin{array}{c}0.81 \\
34.7 \%\end{array}$ & -1.30 & 1.20 \\
\hline $\begin{array}{l}3 \mathrm{~h} \\
\% \text { decrease }\end{array}$ & -0.62 & $\begin{array}{c}0.49 \\
60.5 \%\end{array}$ & -0.78 & $\begin{array}{c}0.49 \\
45.6 \%\end{array}$ & -0.93 & $\begin{array}{c}0.53 \\
57.6 \%\end{array}$ & -1.30 & 1.19 \\
\hline \multicolumn{9}{|c|}{ 5:1 Glucose: picrate test } \\
\hline Blank ${ }^{4}$ & -0.63 & 1.17 & -0.78 & 0.92 & -0.93 & 1.15 & -1.33 & 1.22 \\
\hline $\begin{array}{l}1 / 2 \mathrm{~b} \\
\% \text { decrease }\end{array}$ & -0.63 & $\begin{array}{c}1.01 \\
12.8 \%\end{array}$ & -0.79 & $\begin{array}{c}0.75 \\
18.5 \%\end{array}$ & -0.93 & $\begin{array}{c}1.02 \\
11.4 \%\end{array}$ & -1.31 & 1.42 \\
\hline $\begin{array}{l}1 \mathrm{~h} \\
\% \text { decrease }\end{array}$ & -0.62 & $\begin{array}{c}0.72 \\
38.6 \%\end{array}$ & -0.79 & $\begin{array}{c}0.49 \\
47.0 \%\end{array}$ & -0.93 & $\begin{array}{c}0.77 \\
32.8 \%\end{array}$ & -1.32 & 1.32 \\
\hline $\begin{array}{l}11 / 2 \mathrm{~h} \\
\% \text { decrease }\end{array}$ & -0.62 & $\begin{array}{c}0.49 \\
57.9 \%\end{array}$ & -0.78 & $\begin{array}{c}0.41 \\
55.4 \%\end{array}$ & -0.93 & $\begin{array}{c}0.53 \\
54.1 \%\end{array}$ & -1.32 & 1.42 \\
\hline $\begin{array}{l}2 \mathrm{~h} \\
\% \text { decrease }\end{array}$ & -0.61 & $\begin{array}{c}0.25 \\
79.0 \%\end{array}$ & -0.77 & $\begin{array}{c}0.23 \\
75.5 \%\end{array}$ & -0.92 & $\begin{array}{c}0.25 \\
78.6 \%\end{array}$ & -1.30 & 1.28 \\
\hline
\end{tabular}

1 The half-wave potential $\left(\mathrm{E}_{1 / 2}\right)$ is expressed in volts versus a saturated calomel electrode.

2 The diffusion current $\left(I_{d}\right)$ is expressed in microamperes.

${ }^{3}$ Reduction wave IV was diffuse and not well-defined. Approximate $E_{1 / 2}$ and $I_{d}$ measurements are presented.

${ }^{4}$ A zero time blank was withdrawn immediately after mixing. 


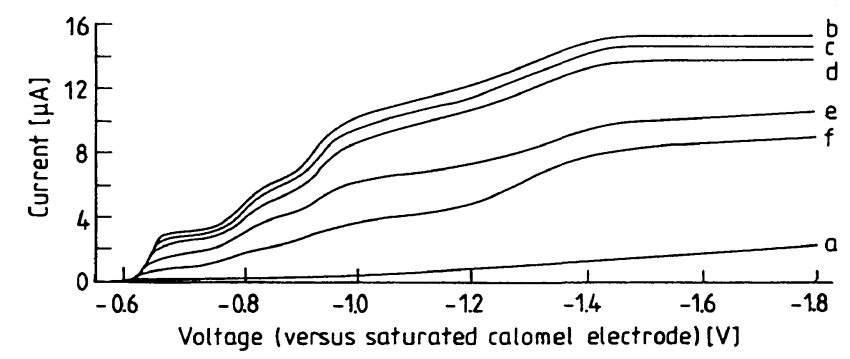

Fig. 1. Polarograms of an aqueous $0.51 \mathrm{~mol} / 1$ sodium hydroxide blank (a), an alkaline picrate blank (b), $1: 1$ (c), $2: 1$ (d), 5:1 (e), and 10:1 (f) glucose : picrate test solutions reacted for 1 hour at $25^{\circ} \mathrm{C}$.

duction waves of glucose: picrate test solutions was calculated against an alkaline picrate blank. For one hour reaction times, the $I_{d}$ of the first reduction wave of glucose: picrate in $1: 1,2: 1$, and $5: 1$ test solutions decreased by $4.0 \%, 19.8 \%$, and $38.6 \%$, respectively (see tab. 2 and fig. 2).

Test solutions containing a 1:1 molar ratio showed a greater decrease for reduction wave 1 than for waves 2 and 3 during a three hour reaction (tab. 2). Similar but more pronounced effects were observed for $2: 1$ test solutions. For $10: 1$ test solutions, the $I_{d}$ of reduction waves 1,2 and 3 was observed to decrease at a faster rate (tab. 3). However, some reactivity pref-

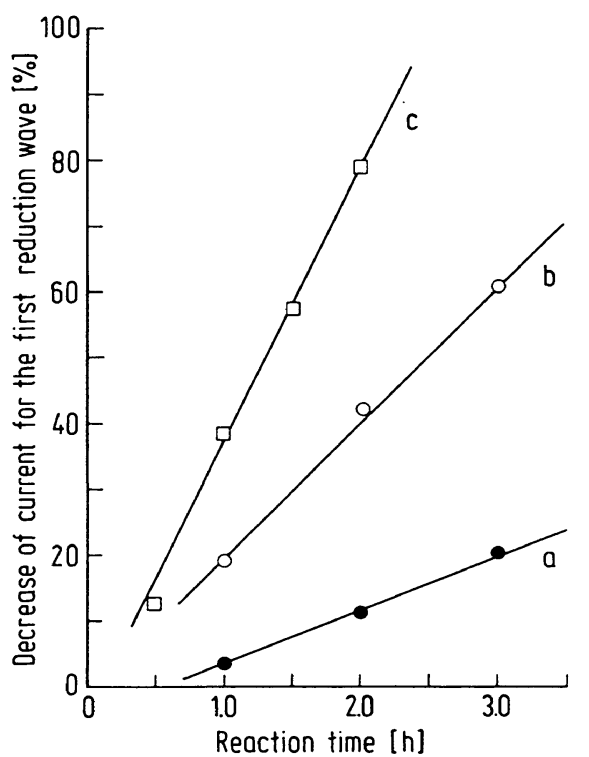

Fig. 2. The relationship between the percent decrease of diffusion current for the first nitro group reduction wave and the reaction time in hours for glucose : picrate test solutions in $0.51 \mathrm{~mol} / 1 \mathrm{NaOH}$ at $25^{\circ} \mathrm{C}$ in the molar ratios of $1: 1$ (a), 2:1 (b), and 5:1 (c), respectively.

erence was shown for wave 1 with a $100 \%$ decrease observed after 90 minutes of reaction time (see fig. 3 ). With increased concentrations of glucose in the range of $2: 1$ to $5: 1$ to $10: 1$, there appears to be an increase in the $I_{d}$ of the 4 th reduction wave.

Tab. 3. Polarographic results of the nitro group reduction waves of glucose : picrate $10: 1$ molar ratio test solutions in 0.51 mol/1 $\mathrm{NaOH}$ at 10 minutes intervals.

\begin{tabular}{|c|c|c|c|c|c|c|c|c|}
\hline \multirow[t]{3}{*}{ Time } & \multicolumn{8}{|c|}{ Picrate reduction waves ${ }^{1,2}$} \\
\hline & \multicolumn{2}{|c|}{$\mathrm{I}$} & \multicolumn{2}{|l|}{ II } & \multicolumn{2}{|l|}{ III } & \multicolumn{2}{|l|}{$\mathrm{IV}^{3}$} \\
\hline & $\overline{\mathrm{E}_{1 / 2}}$ & $\mathrm{I}_{\mathrm{d}}$ & $\overline{E_{1 / 2}}$ & $\mathrm{I}_{\mathrm{d}}$ & $\overline{E_{1 / 2}}$ & $\mathrm{I}_{\mathrm{d}}$ & $\overline{E_{1 / 2}}$ & $\mathrm{I}_{\mathrm{d}}$ \\
\hline \multicolumn{9}{|c|}{$10: 1$ Glucose : picrate test } \\
\hline Blank $^{4}$ & -0.63 & 1.14 & -0.79 & 0.87 & -0.93 & 1.17 & -1.32 & 1.28 \\
\hline $\begin{array}{l}10 \text { min } \\
\% \text { decrease }\end{array}$ & -0.63 & $\begin{array}{l}1.05 \\
7.48 \%\end{array}$ & -0.78 & $\begin{array}{l}0.79 \\
9.19 \%\end{array}$ & -0.93 & $\begin{array}{l}1.12 \\
4.50 \%\end{array}$ & -1.30 & 1.20 \\
\hline $\begin{array}{l}20 \mathrm{~min} \\
\% \text { decrease }\end{array}$ & -0.63 & $\begin{array}{c}0.94 \\
17.2 \%\end{array}$ & -0.78 & $\begin{array}{c}0.71 \\
18.1 \%\end{array}$ & -0.93 & $\begin{array}{c}0.90 \\
22.7 \%\end{array}$ & -1.32 & 1.50 \\
\hline $\begin{array}{l}30 \text { min } \\
\% \text { decrease }\end{array}$ & -0.62 & $\begin{array}{c}0.77 \\
32.1 \%\end{array}$ & -0.78 & $\begin{array}{c}0.66 \\
24.4 \%\end{array}$ & -0.93 & $\begin{array}{c}0.81 \\
30.7 \%\end{array}$ & -1.31 & 1.58 \\
\hline $\begin{array}{l}40 \text { min } \\
\% \text { decrease }\end{array}$ & -0.62 & $\begin{array}{c}0.64 \\
43.6 \%\end{array}$ & -0.78 & $\begin{array}{c}0.55 \\
37.4 \%\end{array}$ & -0.93 & $\begin{array}{c}0.60 \\
48.5 \%\end{array}$ & -1.30 & 1.54 \\
\hline $\begin{array}{l}50 \text { min } \\
\% \text { decrease }\end{array}$ & -0.62 & $\begin{array}{c}0.47 \\
58.6 \%\end{array}$ & -0.78 & $\begin{array}{c}0.47 \\
45.9 \%\end{array}$ & -0.93 & $\begin{array}{c}0.51 \\
56.4 \%\end{array}$ & -1.28 & 1.34 \\
\hline $\begin{array}{l}60 \text { min } \\
\% \text { decrease }\end{array}$ & -0.61 & $\begin{array}{c}0.36 \\
68.5 \%\end{array}$ & -0.78 & $\begin{array}{c}0.41 \\
52.3 \%\end{array}$ & -0.92 & $\begin{array}{c}0.47 \\
59.7 \%\end{array}$ & -1.29 & 1.42 \\
\hline $\begin{array}{l}70 \text { min } \\
\% \text { decrease }\end{array}$ & -0.61 & $\begin{array}{c}0.23 \\
80.2 \%\end{array}$ & -0.77 & $\begin{array}{c}0.32 \\
63.2 \%\end{array}$ & -0.93 & $\begin{array}{c}0.34 \\
70.8 \%\end{array}$ & -1.28 & 1.49 \\
\hline $\begin{array}{l}80 \text { min } \\
\% \text { decrease }\end{array}$ & -0.60 & $\begin{array}{c}0.12 \\
89.9 \%\end{array}$ & -0.76 & $\begin{array}{c}0.23 \\
74.1 \%\end{array}$ & -0.92 & $\begin{array}{c}0.19 \\
83.7 \%\end{array}$ & -1.27 & 1.57 \\
\hline $\begin{array}{l}90 \text { min } \\
\% \text { decrease }\end{array}$ & 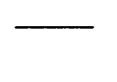 & $\overline{100 \%}$ & -0.76 & $\begin{array}{c}0.13 \\
84.8 \%\end{array}$ & -0.91 & $\begin{array}{c}0.15 \\
87.1 \%\end{array}$ & -1.29 & 1.43 \\
\hline
\end{tabular}

1 The half-wave potential $\left(\mathrm{E}_{1 / 2}\right)$ is expressed in volts versus a saturated calomel electrode.

2 The diffusion current $\left(I_{d}\right)$ is expressed in microamperes.

3 Reduction wave IV was diffuse and not well defined. Approximate $E_{1 / 2}$ and $I_{d}$ measurements are presented.

4 A zero time blank was withdrawn immediately after mixing. 


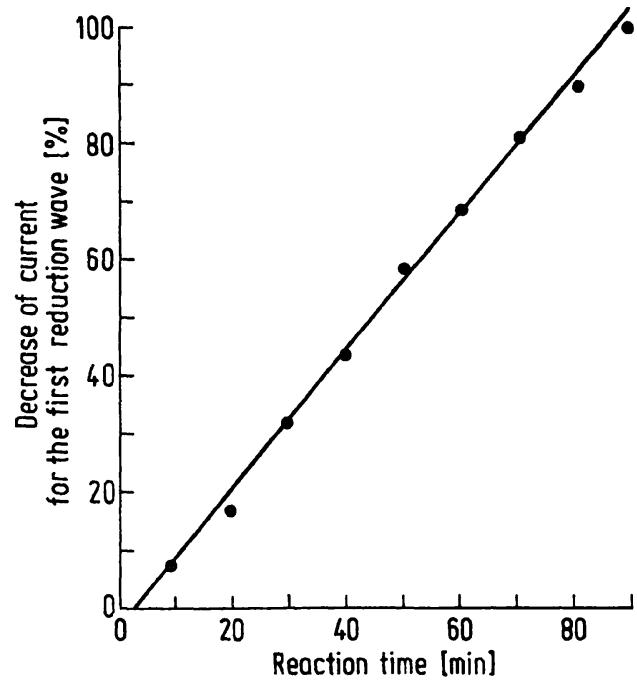

Fig. 3. The relationship between the percent decrease of diffusion current for the first nitro group reduction wave and the reaction time in minutes for $10: 1$ glucose : picrate test solutions in $0.51 \mathrm{~mol} / 1 \mathrm{NaOH}$ at $25^{\circ} \mathrm{C}$.

Polarographic analyses of picramic acid in aqueous $0.51 \mathrm{~mol} / 1 \mathrm{NaOH}$ showed two well defined reduction waves with average $E_{1 / 2}$ values of $-0.76 \mathrm{~V}$ for wave 1 and $-0.92 \mathrm{~V}$ for wave 2 and a broad reduction wave 3 of $-1.35 \mathrm{~V}$ against a saturated calomel electrode (tab. 4). A 10:1 glucose : picramic acid solution showed a decrease in $I_{d}$ of waves 1 and 2 with a relatively constant $I_{d}$ for wave 3 (tab. 5).

Results of the acid/alkali treatment procedure for alkaline picrate blank solutions, and 1:1, 2:1, 5:1 and $10: 1$ glucose:picrate test solutions have been tabulated (see tab. 5). The decrease in the diffusion current observed for reduction waves $1-3$ of the acid/ alkali-regenerated alkaline picrate blank is directly attributed to the $30 \%$ dilution. In addition, there is a loss of diffusion current for reduction wave 4 , which probably shows up as a slight increase in waves 1-3. For alkaline picrate blank solutions, reduction waves 1-3 were recovered. A decrease in the diffusion current of reduction waves $1-3$ was observed for glucose:picrate test solutions. After acid/alkali treatment, taking into consideration the $30 \%$ dilution factor and compensation by the 4th wave, regeneration to the blank level did not occur.

The absorption spectrum of picric acid in $0.51 \mathrm{~mol} / 1$ $\mathrm{NaOH}$ (alkaline picrate blank) showed an intense band at $356 \mathrm{~nm}$ against water as a blank. A study of 10:1 glucose:picrate test solutions in $0.51 \mathrm{~mol} / 1$ $\mathrm{NaOH}$, recorded at 10 minutes intervals, is presented in figure 4. Upon reaction with glucose, the $356 \mathrm{~nm}$ absorbance band decreased in intensity and shifted to $375 \mathrm{~nm}$. A broad shoulder absorbance was also observed to increase between 450 and $550 \mathrm{~nm}$. Absorption spectra of 10:1 glucose:picrate test solutions, reacted for 90 minutes, were compared with spectra of picramic acid in $0.51 \mathrm{~mol} / 1 \mathrm{NaOH}$. Picramic acid had maximum absorbance bands at $317 \mathrm{~nm}$ and 406 $\mathrm{nm}$ with a broad shoulder absorbance in the $450-$ $600 \mathrm{~nm}$ range. When a small amount of picric acid was mixed with picramic acid, only a broad absorbance near $394 \mathrm{~nm}$ appeared, together with the broad shoulder absorbance in the $450-600 \mathrm{~nm}$ region.

Tab. 4. Polarographic results of the nitro group reduction waves of glucose: picramate $10: 1$ molar ratio in $0.51 \mathrm{~mol} / 1 \mathrm{NaOH}$.

\begin{tabular}{|c|c|c|c|c|c|c|}
\hline \multirow[t]{3}{*}{ Time } & \multicolumn{6}{|c|}{ Picramate reduction waves ${ }^{1,2}$} \\
\hline & \multicolumn{2}{|l|}{ I } & \multicolumn{2}{|l|}{ II } & \multicolumn{2}{|l|}{$\mathrm{III}^{3}$} \\
\hline & $\mathrm{E}_{1 / 2}$ & $\mathbf{I}_{\mathbf{d}}$ & $\overline{E_{1 / 2}}$ & $I_{d}$ & $\mathrm{E}_{1 / 2}$ & $\mathbf{I}_{\mathbf{d}}$ \\
\hline \multicolumn{7}{|c|}{$0: 1$ Glucose : picramate blank } \\
\hline $\begin{array}{l}\text { Blank } \\
1 \mathrm{~h} \\
2 \mathrm{~h}\end{array}$ & $\begin{array}{l}-0.76 \\
-0.76 \\
-0.76\end{array}$ & $\begin{array}{l}1.80 \\
1.80 \\
1.80\end{array}$ & $\begin{array}{l}-0.92 \\
-0.92 \\
-0.92\end{array}$ & $\begin{array}{l}1.20 \\
1.20 \\
1.20\end{array}$ & $\begin{array}{l}-1.35 \\
-1.35 \\
-1.35\end{array}$ & $\begin{array}{l}0.70 \\
0.70 \\
0.75\end{array}$ \\
\hline \multicolumn{7}{|c|}{$10: 1$ Glucose : picramate test } \\
\hline Blank $^{4}$ & -0.76 & 1.80 & -0.92 & 1.20 & -1.35 & 0.70 \\
\hline $\begin{array}{l}1 / 2 \mathrm{~h} \\
\% \text { decrease }\end{array}$ & -0.76 & $\begin{array}{c}1.40 \\
22.2 \%\end{array}$ & -0.91 & $\begin{array}{c}0.90 \\
25.0 \%\end{array}$ & -1.40 & 0.70 \\
\hline $\begin{array}{l}1 \mathrm{~h} \\
\% \text { decrease }\end{array}$ & -0.76 & $\begin{array}{c}1.00 \\
44.4 \%\end{array}$ & -0.91 & $\begin{array}{c}0.70 \\
41.7 \%\end{array}$ & -1.39 & 0.75 \\
\hline $\begin{array}{l}11 / 2 \mathrm{~h} \\
\% \text { decrease } \\
2 \mathrm{~h}^{5}\end{array}$ & -0.76 & $\begin{array}{c}0.70 \\
61.1 \%\end{array}$ & -0.91 & $\begin{array}{c}0.40 \\
66.67 \%\end{array}$ & -1.39 & 0.75 \\
\hline
\end{tabular}

1 The half-wave potential $\left(\mathrm{E}_{1 / 2}\right)$ is expressed in volts versus a saturated calomel electrode.

2 The diffusion current $\left(I_{d}\right)$ is expressed in microamperes.

${ }^{3}$ Reduction wave III was diffuse and not well-defined. Approximate $\mathrm{E}_{1 / 2}$ and $\mathrm{I}_{d}$ measurements are presented.

${ }^{4}$ A zero time blank was withdrawn immediately after mixing.

5 Capillary was clogged by precipitate. 
Tab. 5. Acid/alkali nitro group regeneration studies of alkaline picrate blank and glucose: picrate 1:1, 2:1, 5:1 and 10:1 molar ratio test solutions in $0.51 \mathrm{~mol} / \mathrm{l} \mathrm{NaOH}$.

Time

Picrate reduction waves $^{1,2}$

\begin{tabular}{|c|c|c|c|c|c|c|}
\hline I & & II & & III & & $I^{2}{ }^{3}$ \\
\hline$\overline{E_{1 / 2}}$ & $I_{d}$ & $\overline{E_{1 / 2}}$ & $\mathrm{I}_{\mathrm{d}}$ & $\overline{E_{1 / 2}}$ & $I_{d}$ & $\overline{E_{1 / 2}}$ \\
\hline
\end{tabular}

$0: 1$ Alkaline picrate blank

Blank

$2 \mathrm{~h}$

Acid/alkali

$\begin{array}{ll}-0.62 & 1.20 \\ -0.62 & 1.25 \\ -0.62 & 0.90\end{array}$

1.20

0.90

$$
\begin{aligned}
& -0.62 \\
& -0.62
\end{aligned}
$$

1.25

$-0.62$

0.82
0.75

$-0.63$

$-0.62$

1.24

0.75

$-0.62 \quad 0.70$

-0.79
-0.78
-0.76

0.90

0.68

0.65

$\begin{array}{ll}-0.63 & 1.17 \\ -0.61 & 0.23 \\ -0.61 & 0.26\end{array}$

-0.78
-0.77

-0.77
-0.75

0.92

0.23

0.26

$-0.63$

1.17

1.17

$-0.79$

0.90

-0.93
-0.91

-0.93
-0.92

-0.92
-0.92

1.15

0.27

0.22

1.10

0.83

0.45

$-1.32$

$-1.32$

$-1.32$

1.50

1.35

0.15

$11 / 2 \mathrm{~h}$

Acid/alkali

$\begin{array}{llll}-0.63 & -0.79 & -90 & -0.91 \\ - & -0.91\end{array}$

$=\quad-\quad-\quad-\quad \begin{aligned} & -0.91 \\ & -0.91\end{aligned}$

1 The half-wave potential $\left(\mathrm{E}_{1 / 2}\right)$ is expressed in volts versus a saturated calomel electrode.

2 The diffusion current $\left(\mathrm{I}_{\mathrm{d}}\right)$ is expressed in microamperes.

3 Reduction wave IV was diffuse and not well-defined. Approximate $E_{1 / 2}$ and $I_{d}$ measurements are presented.

${ }^{4}$ A zero time blank was withdrawn immediately after mixing.

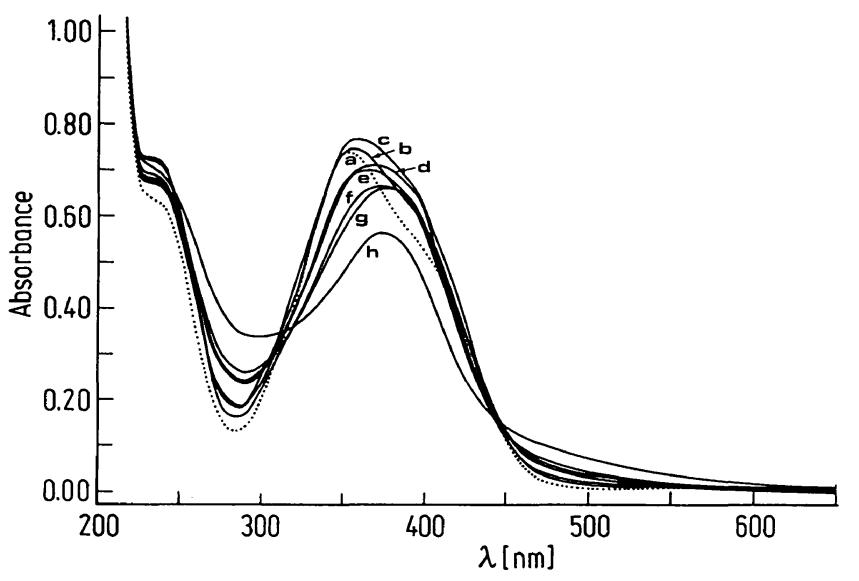

Fig. 4. Absorption spectra of an alkaline picrate blank (a) and of a 10:1 glucose:picrate molar ratio test solution, measured at 10 (b), 20 (c), 30 (d), 40 (e), 50 (f), 60 (g), and $70(\mathrm{~h}) \mathrm{min}$ of reaction time. Blank and test studies were performed in $0.51 \mathrm{~mol} / 1 \mathrm{NaOH}$ at $25^{\circ} \mathrm{C}$.

Alkaline picrate $=356 \mathrm{~nm}$

Glucose picrate $=356 \mathrm{~nm}$

shifted to $375 \mathrm{~nm}$ and a broad shoulder appeared in the $450-550 \mathrm{~nm}$ region
Products of a $10: 1$ glucose: picrate molar ratio test solution were isolated by TLC. Products were identified by comparison of $R_{f}$ values and colours of known reference materials (24). Picric acid was identified as a yellow band with an $R_{f}$ of 0.94 . An orange coloured fluorescent product with an $R_{f}$ of 0.54 was observed for $1: 1,2: 1,5: 1$ and 10:1 molar ratio tests. The fluorophore band excitation and emission maxima were $318 \mathrm{~nm}$ and $545 \mathrm{~nm}$, respectively. Picramic acid was identified as a brown band with an $R_{f}$ of 0.48 . Picramic acid was isolated by TLC for $5: 1$ and $10: 1$ molar ratio test solutions. A yellow coloured band with an $R_{f}$ of 0.41 was also observed.

The IR spectrum of the reddish-brown coloured product separated by TLC was identical to the IR spectrum obtained for the purified picramic acid. The melting point of the product was between 167$168^{\circ} \mathrm{C}$, which was in close agreement with the melting point of similarly tested commercial picramic acid. 
Polarograms of the reddish-brown coloured product and the reference picramic acid were recorded. The product showed two well-defined reduction waves with average $E_{1 / 2}$ values of -0.75 and $-0.92 \mathrm{~V}$ and a broad third reduction wave of $-1.37 \mathrm{~V}$ versus a saturated calomel electrode. These were comparable to the $E_{1 / 2}$ values of $-0.76,-0.92$ and $-1.36 \mathrm{~V}$ observed for the reference picramic acid.

\section{Discussion}

Dilute test solutions were required for polarographic analysis with a constant sodium hydroxide concentration of $0.51 \mathrm{~mol} / \mathrm{l}$. The concentration of alkali has been shown to influence the polarography results (8). Three well-defined nitro group reduction waves and a broad fourth wave were observed for alkaline picrate blank solutions. The $E_{1 / 2}$ values of reduction waves $1-3$ are in agreement with recently published values $(8,29)$. The slight variation in the $E_{1 / 2}$ value of reduction wave 4 may be due to inaccuracies in the measurement of this broad not well-defined wave. The $I_{d}$ values for each of the nitro group reduction waves were stable for three hours (tab. 1). For $1: 1$ glucose:picrate diluted test solutions, the $I_{d}$ of the reduction waves was unchanged during a three hour stability study. Similarly, the $I_{d}$ values for $5: 1$ glucose : picrate diluted test solutions incubated at $25^{\circ} \mathrm{C}$ remained stable for two hours.

For all subsequent analyses, glucose: picrate test solutions were incubated in concentrated form, and diluted prior to polarographic and spectrophotometric analysis. The $I_{d}$ of reduction waves $1-3$ was observed to decrease for all test solutions. In general, the $I_{d}$ of wave 1 decreased faster than that of waves 2 or 3 . A more pronounced response was observed with increased concentrations of glucose and lengthened incubation times. Reduction wave 4 has been attributed to the presence of nitro anion species (8, 29 ). In the present studies, wave 4 is probably due to nitro anions of $1: 1$ and $2: 1$ hydroxide: picrate complexes. The $I_{d}$ of reduction wave 4 was relatively stable for blank, $1: 1$, and $2: 1$ glucose : alkaline picrate studies. The stability of wave 4 is believed to be an indication that glucose is not reactive with nitro anion groups (of $1: 1$ and $2: 1$ hydroxide: picrate complexes) under the present experimental conditions. The slight $I_{d}$ increase of wave 4 for $5: 1$ and $10: 1$ glucose:alkaline picrate may in part be attributed to a nitro anion form of picramic acid (see tabs. 2 and 3). The three reduction waves of picramic acid in 0.51 $\mathrm{mol} / 1 \mathrm{NaOH}$ were comparable to the $\mathrm{E}_{1 / 2}$ values of reduction waves 2, 3 and 4 of alkaline picrate. Based on this observation, it appears that the first nitro reduction wave of picric acid is due to an ortho nitro group.

The colour of the 1:1 glucose:picrate test solution was observed to change slowly from yellow to orange, while the diffusion current of reduction wave 1 decreased by $4 \%$ during one hour of reaction time (tab. 2 ). The orange colour was stable for hours. In contrast, the colour of $10: 1$ glucose : picrate test solutions changed instantaneously to orange, then to reddishbrown in approximately one minute. The corresponding polarographic results indicated that a $7.5 \%$ decrease in the diffusion current for reduction wave 1 was observed with 10 minutes (tab. 3). At the higher concentrations of glucose, the colour changed from yellow to orange to red. This is probably due to different intermediate products formed during the glucose picrate reaction. After 2 hours of reaction time, clogging of the capillary tube was observed for both $5: 1$ and $10: 1$ test solutions.

Cook (21) concluded that the rate at which the colour developed depended upon the glucose concentration and the temperature. Other investigators reported that glucose reduced picric acid to red picramate at higher temperature $(12,15)$. In the present studies, performed at $25^{\circ} \mathrm{C}$, the glucose alkaline picrate reaction was proportional to the glucose concentration and the reaction time (see fig. 2).

In the previous acid/alkali treatment studies the authors were able to quantitatively recover nitro group reduction waves 1, 2 and 3 at the expense of wave 4 (29). This is in agreement with present studies of alkaline picrate blank solutions. However, quantitative recovery of waves 1, 2 and 3 for glucose: alkaline picrate test solutions did not occur, although a minor amount of regeneration of waves 1,2 and 3 did result at the expense of wave 4 (see tab. 5). This is attributed to the conversion of nitro anion groups to nitro groups.

In general the intermediate products did not appear to be available for electrochemical reduction under the experimental conditions employed. The above statement was supported by the following observations. A fluorescent compound was observed to form in $1: 1,2: 1,5: 1$ and $10: 1$ glucose: alkaline picrate test solutions, whereas, picramate spots were observed on the chromatograms of $5: 1$ and $10: 1$ glucose: picrate test aliquots. If picramic acid were the direct and only reduction product of picric acid, the $I_{d}$ values for waves 2 and 3 would be expected to remain constant. However, continued reduction of $10: 1$ glucose: picramate in $0.51 \mathrm{~mol} / \mathrm{l} \mathrm{NaOH}$ indicated that there was a continuous decrease of the $I_{d}$ 's 
of waves 1 and 2 of picramate with a relatively constant diffusion current for wave 4 (tab. 4). This is probably an indication that excess glucose reduces picric acid to 2-amino-4,6-dinitrophenol and 2,6-diamino-4-nitrophenol. It would be convenient to conclude that precipitate formation is responsible for the decrease in the diffusion currents for the $1: 1$ and $2: 1$ test results, but no precipitate was observed for either $1: 1$ or $2: 1$ glucose: alkaline picrate test solutions. The colour was observed to change from yellow to orange. The orange-fluorescent color can be distinguished by TLC from the orange colour produced in the presence of excess sodium hydroxide and picric acid.

The absorption spectra of glucose: alkaline picrate test solutions shifted slowly from $356 \mathrm{~nm}$ to $375 \mathrm{~nm}$ with a broad absorption shoulder in the $450-600 \mathrm{~nm}$ red chromophore region when measured against water. This may affect the determination of creatinine by the Jaffé procedure. Pure alkaline picramate gave absorbance maxima at $212 \mathrm{~nm}, 312 \mathrm{~nm}$ and $404 \mathrm{~nm}$. Ohta \& Morita (19) investigating the visible region had reported an absorbance band near $400 \mathrm{~nm}$. When a mixture of picric acid and picramic acid was measured, the two peaks at $312 \mathrm{~nm}$ and $404 \mathrm{~nm}$ disappared resulting in a broad peak in the $350 \mathrm{~nm}$ to $400 \mathrm{~nm}$ region.

For $1: 1$ and $2: 1$ glucose: alkaline picrate ratios, an orange fluorescent compound was isolated by TLC. Fluorescence diminished in acid solution and upon exposure to UV light under wet conditions. The fluorescent compound was not identified, but it is believed to be an intermediate product. The orange fluorescent compound was also observed for 5:1 and $10: 1$ test solutions.

Products of the glucose-picrate reaction were prepared and isolated from 10:1 glucose:picrate test solutions by incubation at $25^{\circ} \mathrm{C}$ for 90 minutes. A major red-coloured product was isolated and identified as picramic acid; melting point, $R_{f}$ value (24), and IR spectrum (30) were identical with those of the picramic acid standard.

\section{Conclusions}

1. Spectrophotometric studies of $10: 1$ glucose: alkaline picrate test solutions incubated at $25^{\circ} \mathrm{C}$ have identified a broad tailing shoulder absorbance between 450 and $600 \mathrm{~nm}$.

2. Polarographic studies have identified the disappearance of nitro functional groups of picric acid.

3. TLC studies have isolated a red-coloured major product of $R_{f}$ of 0.48 which exhibited characteristics similar to that of picramic acid. The melting point of the isolated product also matched that of picramic acid.

4. A fluorescent orange-coloured minor product was also observed during the TLC studies, with maximum excitation and emission wavelengths of 318 $\mathrm{nm}$ and $545 \mathrm{~nm}$, respectively.

5. I. R. spectroscopy confirmed that the product isolated was picramic acid.

6. Picramic acid is formed in $0.51 \mathrm{~mol} / 1$ sodium hydroxide by $10: 1$ glucose : alkaline picrate test solutions within 10 minutes at $25^{\circ} \mathrm{C}$. The colour of the test solution changed from yellow to orange and then to red within one minute.

\section{Acknowledgement}

The authors gratefully acknowledge Dr. D. G. Lee for the use of the Hewlett-Packard Model 8450A UV/VIS Spectrophotometer, Dr. $A$. E. Emery for his helpful suggestions and the use of a Perkin-Elmer Model 267 infrared grating spectrophotometer, and Mr. D. S. K. Ng for verification of the reactivity of $10: 1$ glucose : alkaline picrate test solutions.

\section{References}

1. Jaffé, M. (1886) Ueber den Niederschlag, welchen Pikrinsäure in normalem Harn erzeugt und über eine neue Reaction des Kreatinins. Z. Physiol. Chem. 10, 391-400.

2. Koštiř, J. V. \& Rábek, V. (1950) The detection of Jaffépositive substances in blood serum by paper partion chromatography, The problem of apparent creatinine. Biochim. Biophys. Acta 5, 210-223.

3. Kammeraat, C. (1978) Modification of the alkaline picrate assay for creatinine to prevent spuriously elevated values by keto acids. Clin. Chim. Acta 84, 119-128.

4. Weise, W. \& Tropp, C. (1928) Untersuchungen über die Jaffesche Pikrinsäurereaktion. Z. Physiol. Chem. 178, 125138.
5. Haugen, H. N. (1954) Glucose and acetone as sources of error in plasma "creatinine" determinations. Scand. J. Clin. Lab. Invest. 6, 17-21:

6. Blass, K. G. \& Ng, D. S. K. (1988) Reactivity of acetoacetate with alkaline picrate: An interference of the Jaffé reaction. Clin. Biochem. 21, 39-47.

7. Fabiny, D. L. \& Ertingshausen, G. (1971) Automated reaction-rate method for determination of serum creatinine with the CentrifiChem. Clin. Chem. 17, 696-700.

8. Ng, D. S. K. \& Blass, K. G. (1987) Reactivity of hydroxide ion with picrate as related to the Jaffé reaction. Microchem. J. $36,89-97$. 
9. Blass, K. G. (1987) Polarographic studies of the reactivity of bilirubin ditaurine conjugate with alkaline picrate. Microchem. J. 35, 334-339.

10. Edwards, K. D. G. \& Whyte, H. M. (1958) The measurement of creatinine in plasma and urine. Aust. J. Exptl. Biol. $36,383-394$.

11. Scandrett, F. J. (1960) Presence of protein in some serum filtrates. Nature 186, 558.

12. Seelig, H. P. \& Wüst, H. (1969) Die Kreatininbestimmung mit der Jaffé-Reaction. Ärztl. Lab. 15, 34-39.

13. Heinegård, D. \& Tiderström, G. (1973) Determination of serum creatinine by a direct colorimetric method. Clin. Chim. Acta 43, 305-310.

14. Husdan, H. \& Rapoport, A. (1968) Estimation of creatinine by the Jaffe reaction. Clin. Chem. 14, 222-238.

15. Hawk, P. B., Oser, B. L. \& Summerson, W. H. (1947) In: Practical Physiological Chemistry, 12th ed., The Blakiston Company, New York, p. 734.

16. Benedict, S. R. (1918) A modification of the Lewis-Benedict method for the determination of sugar in the blood. J. Biol. Chem. 34, 203-207.

17. Willaman, J. J. \& Davison, F. R. (1924) Some modifications of the picric acid method for sugars. J. Agri. Res. 28, 479488.

18. Kaufmann, E. (1933) Ist die Pikrinsäurereaktion für die Bestimmung des Blutzuckers in der Praxis brauchbar? Z. Ges. Exp. Med. 92, 480-489.

19. Ohta, N. \& Morita, H. (1965) Studies on the spectrophotometric determination of glucose with picric acid. Japan Analyst 14, 682-687.
20. Lauson, H. D. (1951) Sources of error in plasma creatinine determination. J. Appl. Physiol. 4, 227-244.

21. Cook, J. G. H. (1972) The development of an automatic analytical system, Ph. D. Thesis, Univ. of Surrey, pp. 171 173.

22. Cook, J. G. H. (1975) Factors influencing the assay of creatinine. Ann. Clin. Biochem. 12, 219-232.

23. Dictionary of Organic Compounds, volumes 1-5 (Pollock, J. R. A. \& Stevens, R., eds.) Eyre and Spottiswoode (Publishers) Ltd., London, England, 4th Edition, 1965, p. 2750.

24. Blass, K. G. (1984) Investigation of picramic acid and methylguanidine formation during the heated Jaffé reaction. Microchem. J. 30, 147-153.

25. Egerer, G. (1918) A modified method for the preparation of picramic acid. J. Biol. Chem. 35, 565-566.

26. Clayton, E. (1930) Picramic acid. J. Soc. Dyers Colourists 46, 365-367.

27. Hodgson, H. H. \& Ward, E. R. (1945) The preferential reduction of nitro-groups in polynitro-compounds. Part III. Picric acid and 3:5-dinitro-o-cresol. An almost qualitative preparation of picramic acid. J. Chem. Soc. 663-665.

28. Anslow, W. K. \& King, H. (1929) The constitution of the red isomeride of creatinine picrate responsible for Jaffe's colour reaction. J. Chem. Soc. 1210-1216.

29. Ng, D. S. K. \& Blass, K. G. (1986) Jaffé reaction products. J. Clin. Chem. Clin. Biochem. 24, 565-570.

30. I. R. Grating Collections (1985) Sadler Research Laboratories, Rock Ville Centre, N. Y., I. R. Spectra number 5982.

K. G. Blass, Ph. D.

Professor of Chemistry

Department of Chemistry

University of Regina

Regina, Saskatchewan

CANADA S4S 0A2 
